\title{
Analisa Pengendalian Kualitas Menggunakan Metode Seven Tools untuk Meminimalkan Return Konsumen di PT. XYZ
}

\author{
Indah Nursyamsi ${ }^{1 *}$, Ade Momon ${ }^{2}$ \\ ${ }^{1,2}$ Program Studi Teknik Industri, Fakultas Teknik, Universitas Singaperbangsa Karawang \\ *Koresponden email: nursyamsiindah88@gmail.com
}

Diterima: 7 Desember 2021

Disetujui: 13 Januari 2022

\begin{abstract}
To overcome quality problems regarding product defects that occur in the company, it is necessary to do an analysis related to the problems that occur and it is necessary to plan improvements to reduce consumer returns. This study aims to analyze and plan improvement plans using the Quality Control Circle (QCC) method using Seven Tools. The Seven Tools used consist of a check sheet, run chart, histogram, scatter diagram, Pareto diagram, cause and effect diagram (fishbone diagram), and control chart. The research was conducted using the interview method with the parties involved with the object and problem. The research data taken is the company's historical data in 2020. The results show that product defects can be caused by various factors such as humans, machines, climate or weather and storage methods. The criteria for defects that often occur in the company are damaged products due to fractures, rusty products, and product sizes that do not match. It can be seen from the criteria for these defects, improvements that can be made are by providing suggestions to overcome the problem so as to reduce the returns that occur in the company.
\end{abstract}

Keywords: defect, quality, quality control circle, seven tools, product, return

\begin{abstract}
Abstrak
Untuk mengatasi permasalahan kualitas mengenai cacat produk yang terjadi di perusahaan perlu dilakukannya analisa terkait dengan permasalahan yang terjadi dan perlu adanya perencanaan perbaikan untuk mengurangi return konsumen. Penelitian ini bertujuan untuk menganalisa dan merencanakan perencanaan perbaikan menggunakan metode Quality Control Circle (QCC) dengan menggunakan Seven Tools. Seven Tools yang digunakan terdiri dari checksheet, run chart, histogram, scatter diagram, diagram pareto, cause and effect diagram (fishbone diagram), dan control chart. Penelitian dilakukan dengan metode wawancara bersama pihak yang terlibat dengan objek dan permasalahan. Data penelitian yang diambil merupakan data historis perusahaan tahun 2020. Hasil penelitian menunjukan adanya cacat produk dapat disebabkan karena berbagai macam faktor seperti manusia, mesin, iklim atau cuaca dan metode penyimpanan. Kriteria cacat yang sering terjadi di perusahaan yaitu produk rusak karena patah, produk berkarat, dan ukuran produk tidak sesuai. Dilihat dari kriteria cacat tersebut, perbaikan yang dapat dilakukan yaitu dengan memberikan saran untuk mengatasi masalah sehingga dapat mengurangi return yang terjadi di perusahaan.
\end{abstract}

Kata Kunci: cacat, kualitas, quality control circle, seven tools, produk, return

\section{Pendahuluan}

Pengendalian kualitas merupakan teknik yang dilakukan mulai dari proses sebelum dimulainya produksi, jalannya proses produksi sampai akhir proses produksi. Pengendalian kualitas dilakukan untuk menghasilkan produk yang memenuhi standar yang diinginkan dan direncanakan, serta untuk meningkatkan kualitas produk yang tidak memenuhi standar yang ditentukan agar sebisa mungkin dapat mencapai kualitas yang memadai [1]. Karena apabila perusahaan memiliki kualitas yang baik, maka perusahaan tersebut dapat dikatakan sudah memenuhi standar yang di rencanakan dan diinginkan.

Kualitas produk merupakan kemampuan suatu produk untuk menjalankan fungsinya, termasuk daya tahan, ketepatan waktu operasi, perbaikan waktu serta atribut lainnya yang bernilai. Kualitas memainkan peran penting dalam industri manufaktur, karena berfungsi sebagai kriteria untuk menilai kesiapan industri [2]. Dalam proses produksi suatu perusahaan sering dijumpai ketidaksesuaian dengan standar produk yang dihasilkan yaitu produk yang dihasilkan rusak atau cacat. Perusahaan perlu melakukan perbaikan untuk menghindari dan mengurangi cacat produk. Produk cacat adalah produk yang tidak memenuhi standar kualitas yang telah ditetapkan [3].

PT. XYZ merupakan salah satu perusahaan yang bergerak dalam industri manufaktur Dies, Jig, Press Part, Tools, dan industri mesin lainnya. Pada keseluruhan proses produksi di PT. XYZ masih 


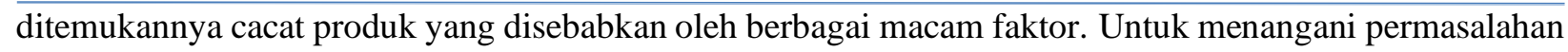
tersebut, perlu dilakukan analisa dalam merencanakan rencana perbaikan kualitas menggunakan Seven Tools untuk mencari solusi terhadap ketidaksesuaian produk agar dapat mencapai kinerja standar dalam bentuk zero defect. Pengendalian kualitas dilakukan untuk memastikan produk dan layanan yang diproduksi oleh perusahaan telah memenuhi standar kualitas yang ditetapkan sehingga memenuhi standar tersebut [4].

Adapun penelitian terdahulu yang dijadikan sebagai acuan pada penelitian ini [5]. Quality Control Circle adalah suatu metode yang dapat digunakan untuk menganalisa dan memecahkan suatu masalah di perusahaan terkait dengan permasalahan pengendalian kualitas produk perusahaan. Pengendalian kualitas yang dilakukan yaitu menggunakan Seven Tools yang digunakan untuk mengidentifikasi penyebab terjadinya defect ban ring 20 dan menganalisis apakah defect yang terjadi masih dalam batas pengendalian. Kemudian dilakukan perbaikan dengan cara memberikan usulan perbaikan guna meningkatkan kualitas ban ring 20 [6]. Metode Quality Control Circle (QCC) dapat menghasilkan pemecahan masalah bagi manajemen dan memungkinkan untuk melihat seberapa efektifnya tingkat perbaikan atau peningkatan yang dilakukan.

\section{Metode Penelitian}

Urutan metode pada penelitian ini digambarkan dengan diagram alir (Flow Chart) pada Gambar 1.

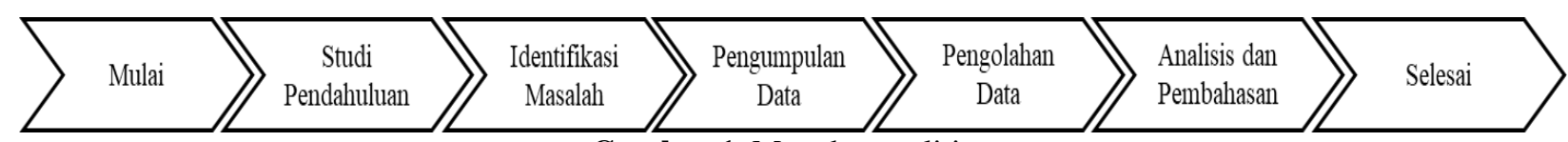

Gambar 1. Metode penelitian

Sumber: [7]

Tahapan penelitian, diantaranya:

a. Mulai, merupakan fase yang menandai dimulainya penelitian.

b. Studi Pendahuluan, fase ini adalah fase mencari informasi yang berkaitan dengan penelitian, misalnya studi literatur dan studi lapangan.

c. Identifikasi Masalah, fase ini merupakan tahap untuk mengidentifikasi dan merumuskan masalah pada objek penelitian yang muncul di perusahaan. Permasalahan yang muncul berupa cacat pada produk yang diproduksi disebabkan karena berbagai faktor.

d. Pengumpulan Data, data yang digunakan adalah data sekunder dan data primer. Data primer diperoleh melalui observasi langsung dilapangan. Sedangkan data sekunder berupa data historis perusahaan periode Januari sampai Desember 2020.

e. Pengolahan Data, fase ini merupakan fase pengolahan data yang menggunakan tujuh alat bantu kegiatan Quality Control Circle atau biasa disebut dengan Seven Tools.

f. Analisis dan Pembahasan, Pada fase ini hasil pengolahan data dianalisis dan didiskusikan.

g. Selesai, merupakan fase yang menandai puncak penelitian atau telah selesainya penelitian yang dilakukan.

\section{Tujuh alat kegiatan Quality Control Circle (QCC)}

Seven Tools adalah alat untuk membantu menganalisis dan menyelesaikan masalah kualitas pada suatu produk perusahaan atau industri [8]. Metode ini merupakan metode grafis yang paling sederhana untuk menyelesaikan masalah [9]. Tujuh tools tersebut, [10] diantaranya:

a. Check Sheet, merupakan lembar pemeriksaan sederhana yang tujuannya adalah untuk mencatat agar mempermudah proses pengumpulan data sehingga data tersebut rapi dan teratur [11].

b. Run Chart (Stratifikasi), merupakan tools untuk menganalisis atau mengklasifikasikan suatu masalah kedalam kelompok-kelompok yang lebih kecil yang merupakan bagian utama dari permasalahan.

c. Fishbone Diagram, merupakan tools diagram sebab akibat untuk mengidentifikasi sebab utama dari suatu masalah. Analisis yang dilakukan yaitu melalui sesi brainstorming [12].

d. Histogram, merupakan tools berbentuk diagram batang yang menunjukkan tingkat variasi pengukuran data. Histogram dikenal sebagai grafik distribusi frekuensi [12].

e. Scatter Diagram, merupakan tools yang berbentuk diagram pencar untuk menggambarkan tingkat kemungkinan hubungan antara dua variabel dengan kekhususan atau sebab dan akibat yang berbeda [13]. 
f. Pareto Diagram, merupakan tools berbentuk bagan yang berisikan diagram batang dan diagram garis. Diagram batang menunjukkan klasifikasi nilai data. Sedangkan diagram garis mewakili total data kumulatif [14].

g. Control Chart, merupakan peta atau grafik untuk memberi gambaran perubahan proses dari waktu ke waktu dan menggambarkan stabilitas suatu proses kerja [15].

1) Upper Control Limit (UCL), yaitu batas kendali atas penyimpangan yang diperbolehkan [16]

2) Central Line (CL), yaitu garis yang menggambarkan bahwa tidak ada penyimpangan dari karakteristik sampel. Grafik ini berisi garis tengah yang mewakili nilai sigma karakteristik kualitas yang terkait dengan keadaan yang terkendali [17].

3) Lower Control Limit (LCL), yaitu data pada batas kontrol bawah yang dihitung dari nilai baku [18].

\section{Hasil dan Pembahasan}

Data penelitian yang digunakan meliputi data Delivery Purchase Order dan data return konsumen bulan Januari sampai Desember 2020 yang dapat dilihat pada Tabel 1.

Tabel 1. Rekapitulasi delivery purchase order dan return konsumen

\begin{tabular}{clcc} 
No. & Bulan & $\begin{array}{c}\text { Total } \\
\text { Pengiriman } \\
(\text { Pcs })\end{array}$ & $\begin{array}{c}\text { Reject per Bulan } \\
(\text { Pcs })\end{array}$ \\
\hline 1. & Januari & 18100 & 290 \\
2. & Februari & 19800 & 243 \\
3. & Maret & 20400 & 279 \\
4. & April & 18200 & 357 \\
5. & Juli & 2000 & 9 \\
6. & Agustus & 1000 & 8 \\
7. & September & 8605 & 288 \\
8. & Oktober & 10486 & 253 \\
9. & November & 10050 & 300 \\
10. & Desember & 8535 & 286 \\
\hline \multicolumn{4}{c}{ Total } \\
\hline \multicolumn{4}{c}{ Sumber: PT. XYZ (2021) }
\end{tabular}

Pengolahan data menggunakan tujuh alat kegiatan Quality Control Circle (QCC) atau biasa disebut Seven Tools. Hasil dari pengolahan data menggunakan Seven Tools diantaranya:

a. Check Sheet (Lembar Pemeriksaan)

Tabel 2. Lembar pemeriksaan

\begin{tabular}{|c|c|c|c|c|}
\hline No. & Bulan & $\begin{array}{l}\text { Total Pengiriman } \\
\text { (Pcs) }\end{array}$ & $\begin{array}{l}\text { Reject per } \\
\text { Bulan (Pcs) }\end{array}$ & Keterangan \\
\hline 1. & Januari & 18100 & 290 & Produk Rusak \\
\hline 2. & Februari & 19800 & 243 & Produk Rusak \\
\hline 3. & Maret & 20400 & 279 & Produk Rusak \\
\hline 4. & April & 18200 & 357 & Produk Rusak \\
\hline 5. & Juli & 2000 & 9 & Ukuran Produk Tidak Sesuai \\
\hline 6. & Agustus & 1000 & 8 & Produk Rusak \\
\hline 7. & September & 8605 & 288 & Produk Rusak \\
\hline 8. & Oktober & 10486 & 253 & $\begin{array}{c}\text { Produk Berubah Warna } \\
\text { (Berkarat) }\end{array}$ \\
\hline 9. & November & 10050 & 300 & $\begin{array}{c}\text { Produk Berubah Warna } \\
\text { (Berkarat) }\end{array}$ \\
\hline \multirow[t]{2}{*}{10} & Desember & 8535 & 286 & $\begin{array}{c}\text { Produk Berubah Warna } \\
\text { (Berkarat) }\end{array}$ \\
\hline & Total & 117176 & 2313 & \\
\hline
\end{tabular}


Berdasarkan Tabel 2, didapatkan lembar pemeriksaan mengenai jumlah defect periode JanuariDesember 2020 dan keterangan terkait penyebab defect yang terjadi. Pada tabel 2 tidak adanya produksi pada bulan Mei-Juni sehingga pada bulan tersebut tidak ada jumlah reject yg dihasilkan.

b. Run Chart (Stratifikasi)

Stratifikasi return konsumen berguna untuk mengidentifikasi produk apa saja yang di return konsumen. Jenis return konsumen antara lain:

1) Produk Rusak : Cacat atau Patah

2) Produk Tidak Sesuai : Ukuran Produk Tidak Sesuai

3) Produk Berubah Warna : Metode penyimpanan barang yang berpindah dari ruangan ber-AC ke ruangan tidak ber AC dan iklim atau cuaca yang berubah-ubah mengakibatkan perubahan warna asli produk.

c. Fishbone Diagram

Dalam menentukan penyebab masalah peneliti menggunakan diagram fishbone untuk mendeskripsikan atau menggambarkan masalah. Hasil analisa diagram fishbone dapat dilihat pada Gambar 2.

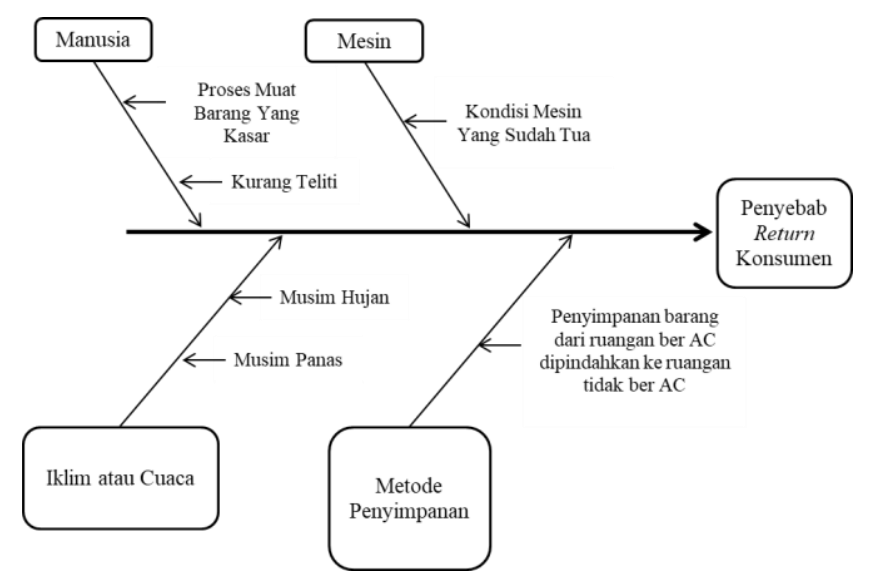

Gambar 2. Diagram Fishbone

Sumber: Pengolahan data (2021)

Pada diagram fishbone Gambar 2 didapatkan penyebab adanya return konsumen. Maka masalah dominan return konsumen dapat dilihat pada Tabel $\mathbf{3}$ dibawah ini.

Tabel 3. Tabel sebab akibat

\begin{tabular}{|c|c|c|c|}
\hline Faktor & Sebab & Akibat & Saran Perbaikan \\
\hline \multirow{2}{*}{$\begin{array}{c}\text { Metode } \\
\text { Penyimpanan }\end{array}$} & \multirow{2}{*}{$\begin{array}{l}\text { Penyimpanan barang yang } \\
\text { tadinya disimpan didalam } \\
\text { ruangan ber AC dipindahkan } \\
\text { kedalam ruangan tidak ber AC }\end{array}$} & Produk Rusak & \multirow{2}{*}{$\begin{array}{l}\text { Disimpan Pada } \\
\text { Gudang Khusus } \\
\text { dengan SOP } \\
\text { Penyimpanan }\end{array}$} \\
\hline & & $\begin{array}{c}\text { Produk Berubah Warna } \\
\text { (Berkarat) }\end{array}$ & \\
\hline $\begin{array}{l}\text { Iklim atau } \\
\text { Cuaca }\end{array}$ & $\begin{array}{l}\text { Karena musim yang berubah } \\
\text { dari musim panas ke musim } \\
\text { hujan maupun sebaliknya }\end{array}$ & $\begin{array}{l}\text { Produk Berubah Warna } \\
\text { (Berkarat) }\end{array}$ & $\begin{array}{l}\text { Disimpan Pada } \\
\text { Gudang Khusus } \\
\text { dengan SOP } \\
\text { Penyimpanan }\end{array}$ \\
\hline \multirow{2}{*}{ Manusia } & Kurang teliti & $\begin{array}{c}\text { Ukuran Produk Tidak } \\
\text { Sesuai }\end{array}$ & SOP Pekerja \\
\hline & $\begin{array}{l}\text { Proses muat barang yang kasar } \\
\text { saat akan pengiriman }\end{array}$ & Produk Rusak & $\begin{array}{l}\text { SOP Proses Muat } \\
\text { Barang }\end{array}$ \\
\hline Mesin & Kondisi mesin yang sudah tua & $\begin{array}{l}\text { Ukuran Produk Tidak } \\
\text { Sesuai }\end{array}$ & $\begin{array}{l}\text { SOP Pemeliharaan } \\
\text { Mesin }\end{array}$ \\
\hline
\end{tabular}

Sumber: Pengolahan data (2021) 
d. Histogram (Diagram Batang)

Dari Tabel 1 didapatkan grafik histogram komplain konsumen tahun 2020 yang dapat dilihat pada Grafik 1.

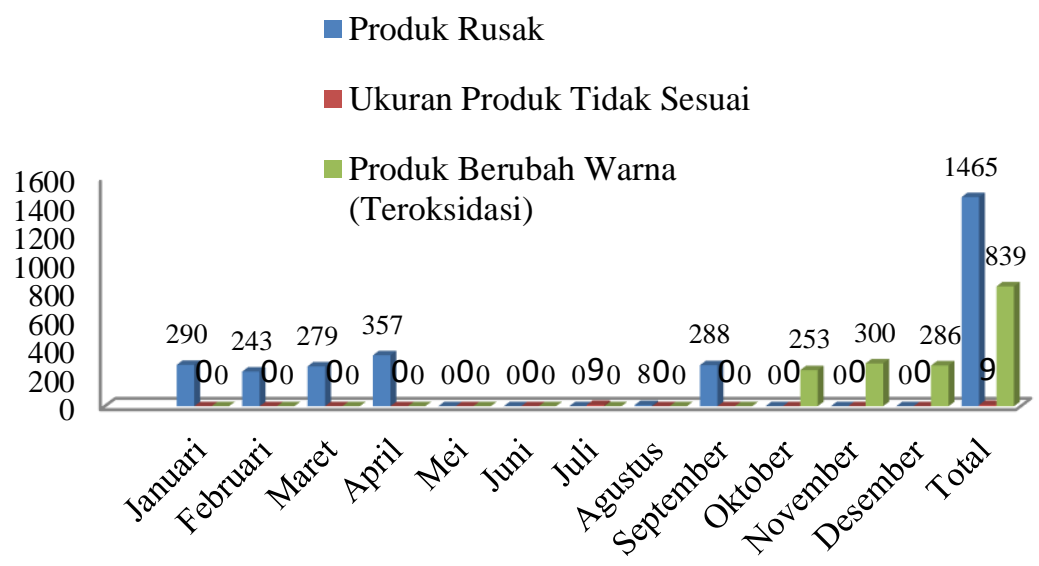

Grafik 1. Histogram komplain konsumen

Sumber: Pengolahan data (2021)

e. Scatter Diagram (Diagram Pencar)

Pada data Delivery Purchase Order dan Return konsumen pada Tabel 2 didapatkan hubungan antara data jumlah komplain konsumen dalam satu tahun sehingga diperoleh scatter diagram seperti pada Grafik 2.

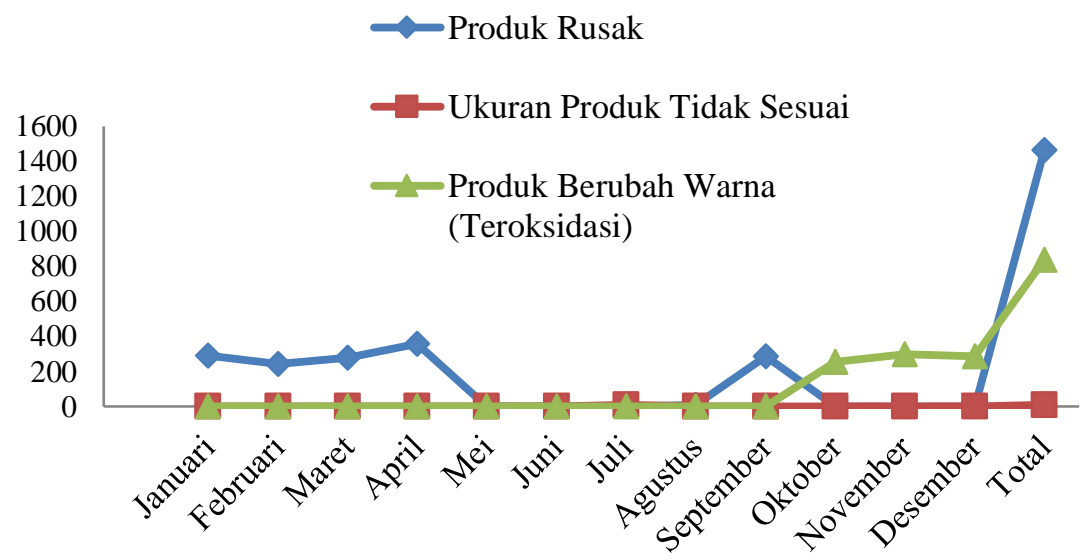

Grafik 2. Scatter Diagram Komplain Konsumen Sumber: Pengolahan Data (2021)

\section{f. Pareto Diagram}

Berdasarkan data pada Tabel 1 didapatkan persentase jenis komplain konsumen pada Tabel 4. Melalui Tabel 4 ini kita bisa melihat secara detail hal-hal mengenai komplain pelanggan.

Tabel 4. Persentase jenis komplain konsumen

\begin{tabular}{cccc}
\hline Jenis Komplain & Total Komplain & $\%$ & \% Kum \\
\hline $\begin{array}{c}\text { Produk Rusak } \\
\text { Ukuran Produk Tidak } \\
\begin{array}{c}\text { Sesuai } \\
\text { Produk Berubah Warna } \\
\text { (Teroksidasi) }\end{array}\end{array}$ & 1465 & 63.3 & 63.3 \\
\hline Total & 939 & 0.4 & 63.7 \\
\hline
\end{tabular}

Sumber: Pengolahan data (2021) 
Pada Tabel 4 diatas dapat dilihat produk rusak memiliki persentase sebesar 63,3\% dan untuk ukuran produk yang tidak sesuai sebesar $0,4 \%$ untuk produk berubah warna (teroksidasi) sebesar 36,3\%. Sehingga diagram Pareto dari persentase jumlah komplain konsumen dapat dilihat pada Grafik 3.

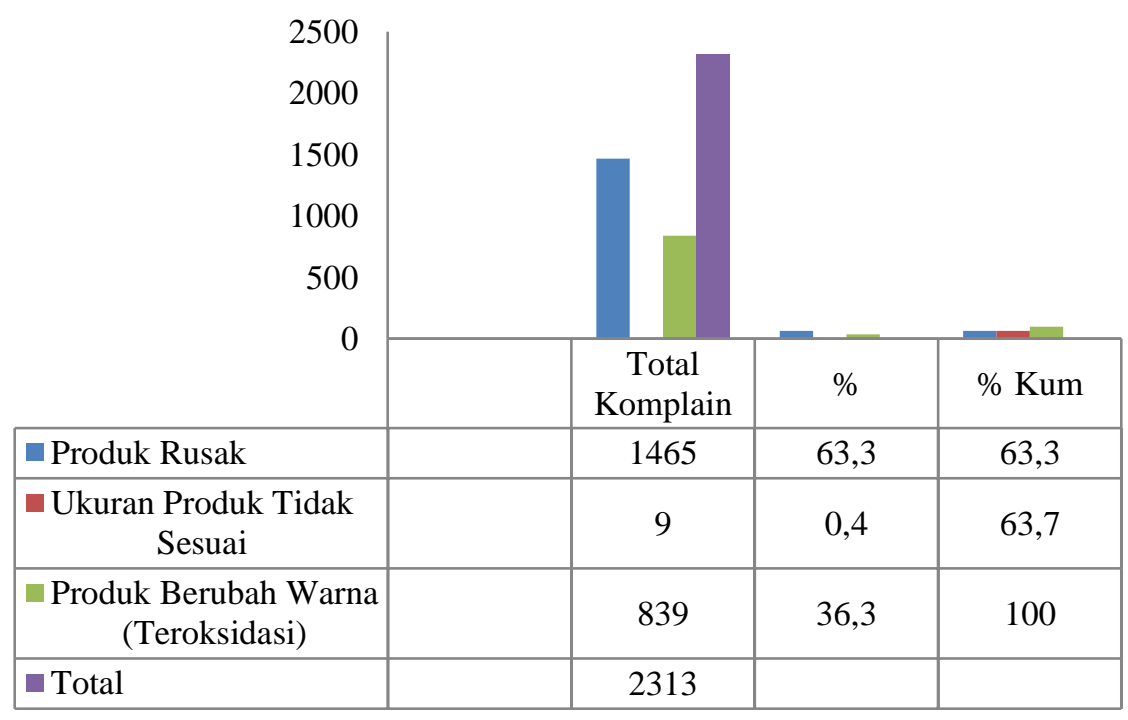

Grafik 3. Pareto diagram komplain konsumen Sumber: Pengolahan data (2021)

\section{g. Control Chart (Peta Kendali)}

Pada Tabel 5 menunjukkan data hasil perhitungan batas kendali bulan Januari sampai Desember tahun 2020. Dari hasil perhitungan pada Tabel 5 didapatkan control chart yang dapat dilihat pada Grafik 4.

Tabel 5. Perhitungan batas kendali Januari-Desember 2020

\begin{tabular}{|c|c|c|c|c|c|c|c|c|}
\hline No. & Bulan & $\begin{array}{c}\text { Total } \\
\text { Pengiriman } \\
\text { (Pcs) per bulan }\end{array}$ & $\begin{array}{c}\text { Reject per } \\
\text { Bulan (Pcs), } \\
\text { (np) }\end{array}$ & $\begin{array}{c}\text { Persentase } \\
\text { Kerusakan }(\mathrm{P})\end{array}$ & p bar & CL & UCL & LCL \\
\hline 1. & Januari & 18100 & 290 & 1.60 & 0.020 & 0.016 & 0.020 & 0.020 \\
\hline 2. & Februari & 19800 & 243 & 1.23 & 0.020 & 0.012 & 0.020 & 0.020 \\
\hline 3. & Maret & 20400 & 279 & 1.37 & 0.020 & 0.014 & 0.020 & 0.020 \\
\hline 4. & April & 18200 & 357 & 1.96 & 0.020 & 0.020 & 0.020 & 0.020 \\
\hline 5. & Juli & 2000 & 9 & 0.45 & 0.020 & 0.005 & 0.020 & 0.020 \\
\hline 6. & Agustus & 1000 & 8 & 0.80 & 0.020 & 0.008 & 0.020 & 0.020 \\
\hline 7. & September & 8605 & 288 & 3.35 & 0.020 & 0.033 & 0.020 & 0.020 \\
\hline $8 .$. & Oktober & 10486 & 253 & 2.41 & 0.020 & 0.024 & 0.020 & 0.020 \\
\hline 9. & November & 10050 & 300 & 2.99 & 0.020 & 0.030 & 0.020 & 0.020 \\
\hline \multirow[t]{2}{*}{10.} & Desember & 8535 & 286 & 3.35 & 0.020 & 0.034 & 0.020 & 0.020 \\
\hline & & 117176 & 2313 & & & & & \\
\hline
\end{tabular}




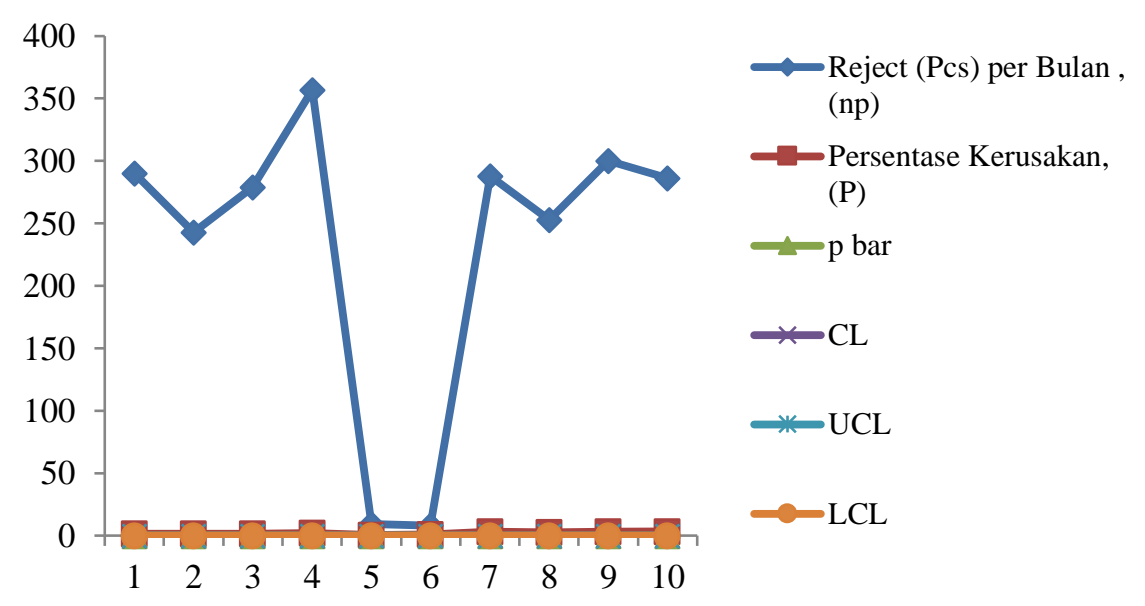

Grafik 4. Control Chart

Sumber: Pengolahan data (2021)

\section{Kesimpulan}

Berdasarkan pengolahan data pada penelitian yang telah dilakukan dapat disimpulkan bahwa banyaknya reject produk yang tidak terkendali di PT. XYZ disebabkan karena berbagai macam faktor diantaranya metode penyimpanan barang dari ruangan ber AC ke ruangan tidak ber-AC, perubahan iklim atau cuaca, manusia atau pekerja yang kurang teliti pada saat proses muat barang, dan kondisi mesin yang sudah tua. Dari faktor-faktor tersebut maka PT. XYZ perlu membuat atau memperbaiki Standar Operasional Prosedur (SOP). SOP yang perlu diperbaiki diantaranya yaitu SOP penyimpanan, SOP pekerja, SOP proses muat barang, dan SOP pemeliharaan mesin.

\section{Referensi}

[1] D. Diniaty, F. Hanum, and M. I. Hamdy, "Analisis Pengendalian Mutu (Quality Control) CPO (Crude Palm Oil) pada PT. XYZ,” J. Tek. Ind., vol. 5, no. 2, pp. 92-99, 2019.

[2] L. L. Salomon and N. Denata, "Strategi Peningkatan Mutu Part Bening Menggunakan Pendekatan Metode Six Sigma (Studi Kasus Departemen Injection Di PT. KG),” J. Ilmial Tek. Ind., vol. 3, no. 3, pp. 156-165, 2015.

[3] W. Hetharia and H. Poernomo, "Analisis Quality Control Terhadap Tingkat Kerusakan Produk Pada PT. Van Glass Surabaya," J. Ekon. Manaj., vol. 4, no. 45, pp. 117-132, 2019.

[4] Y. Syahrullah and M. R. Izza, "Integrasi Fmea Dalam Penerapan Quality Control Circle (QCC) Untuk Perbaikan Kualitas Proses Produksi Pada Mesin Rapier," J. Rekayasa Sist. Ind., vol. 6, no. 2, pp. 7885, 2021.

[5] D. A. Styawan, Wahyudin, and Hamdani, "Penerapan Line Balancing untuk Meningkatkan Proses Perakitan Control Panel di Line Service Part pada PT . Kawai Indonesia Plant 3," J. Serambi Eng., vol. VI, no. 4, 2021.

[6] A. E. Saputra and N. A. Mahibubah, "Analisis Seven Tools Pada Pengendalian Kualitas Proses Vulkanisir Ban 1000 Ring 20 di CV Citra Buana Mandiri Surabaya," J. STRING (Satuan Tulisan Ris. dan Inov). Teknol., vol. 5, no. 3, 2021.

[7] Nurhayati, D. Herwanto, and Hamdani, "Analisis Produktivitas Mesin Filling Auto Cup Sealer 1 dengan Metode Overall Equipment Effectiveness pada PT. Prima Kemasindo," J. Serambi Eng., vol. VI, no. 4, pp. 2248-2255, 2021.

[8] W. W. Dharsono, "Penerapan Quality Control Circle Pada Proses Produksi Wafer Guna Mengurangi Cacat Produksi (Studi Kasus di PT XYZ Jakarta)," J. FATEKSA J. Teknol. dan Rekayasa, vol. 2, no. 1, pp. 31-39, 2017.

[9] D. Rachmawati R and M. M. Ulkhaq, "Aplikasi Metode Seven Tools Dan Analisis 5W + 1H Untuk Mengurangi Produk Cacat Pada PT. Berlina, TBK," J. Ind. Eng. Online, vol. 5, no. 4, 2015.

[10] I. Idris, R. aditya Sari, and Wulandari, "Pengendalian Kualitas Tempe Dengan Metode Seven Tools," J. Teknovasi, vol. 03, pp. 66-80, 2016.

[11] M. M. Ulkhaq, S. N. W. Pramono, and R. Halim, "Aplikasi Seven Tools Untuk Mengurangi Cacat Produk Pada Mesin Communite dI PT. Masscom Graphy, Semarang," J. PASTI, vol. XI, no. 3, pp. 220-230. 
[12] A. M. Rani and W. Setiawan, "Menganalisis Defect Sanding Mark Unit Pick Up Tmc Dengan Metode Seven Tools PT. ADM," J. Integr. Sist. Ind., vol. 3, no. 1, 2016.

[13] T. P. Matondang and M. M. Ulkhaq, "Aplikasi Seven Tools untuk Mengurangi Cacat Produk White Body pada Mesin Roller," J. Sist. dan Manaj. Ind., vol. 2, no. 2, pp. 59-66, 2018.

[14] A. Merjani and I. Kamil, "Penerapan Metode Seven Tools dan PDCA (Plan Do Check Action ) Untuk Mengurangi Cacat Pengelasan Pipa," J. Profisiensi, vol. 9, no. 1, pp. 124-131, 2021.

[15] N. Aziza and F. B. Setiaji, "Pengendalian Kualitas Produk Mebel Dengan Pendekatan Metode Seven Tools," Tek. Eng. Sains J., vol. 4, pp. 27-34, 2020.

[16] Z. Nitafiyah, "Analisis Pengendalian Kualitas Produk Koran Pada PT. Radar Sulteng Membangun di Kota Palu,” J. ILMU Manaj. Univ. TADULAKO, vol. 5, no. 9, pp. 287-297, 2019.

[17] R. Arifianti, “Analisis Kualitas Produk Sepatu Tomkins," J. Din. Manaj., vol. 4, no. 1, pp. 46-58, 2013.

[18] H. Tarmizi and S. N. Indriyani, "Metode Control Chart Dan Fishbone Terhadap Produk Power House Pada Unit Pengolahan Sampah," J. Ekon. dan Ind., vol. 21, no. 1, pp. 35-44, 2020. 